\title{
ADOLESCENCIA Y JUVENTUD: DE LAS NOCIONES A LOS ABORDAJES
}

\author{
OSCAR DÁVILA LEÓN ${ }^{*}$
}

\begin{abstract}
RESUMEN
En el texto se discuten las nociones de adolescencia y juventud, como los abordamientos disciplinarios que de manera contemporánea se han hecho sobre dichas nociones; donde ya no resulta una novedad, pero sí una necesidad, el pluralizar: la necesidad de hablar y concebir diferentes «adolescencias» y «juventudes», en un amplio sentido de las heterogeneidades que se pueden presentar y visualizar entre adolescentes y jóvenes. Aquello cobra vigencia y sentido, de momento que concebimos las categorías de adolescencia y juventud como una construcción sociohistórica, cultural y relacional en las sociedades contemporáneas, donde los esfuerzos en la investigación social en general, y en los estudios de juventud en particular, han estado centrado en dar cuenta de la etapa que media entre la infancia y la adultez, las que a su vez, también se constituyen en categorías fruto de construcciones y significaciones sociales en contextos históricos y sociedades determinadas, en un proceso de permanente cambio y resignificaciones.

Se rescatan los avances en el campo de la investigación en temáticas de adolescencia y juventud a tiempos actuales, y se plantean algunas interrogantes sobre el paso de la adolescencia/juventud a la edad adulta, que ayuden en delimitar las dimensiones y variables que pueden aportar mayores claridades al análisis y sus eventuales impactos en el diseño y definición de políticas hacia estos sujetos sociales.
\end{abstract}

PALABRAS CLAVE: ADOLESCENCIA, JUVENTUD, TRAYECTORIAS JUVENILES

* Asistente Social, CIDPA Valparaíso. E-Mail: oscar@cidpa.cl. 


\section{RESUMO}

Neste texto são discutidas as noções de adolescência e juventude como abordagens disciplinares que atualmente são feitas sobre estas noções e que já não são novidade, mas sim uma necessidade; o pluralizar, a necessidade de falar e conceber diferentes «adolescências» e «juventudes» em um amplo sentido das heterogeneidades que podem ser apresentadas e visualizadas entre adolescentes e jovens.

Isto requer cuidado e observação no momento em que concebemos as categorias de adolescência e juventude como uma construção sócio histórica, cultural e relacional nas sociedades contemporâneas, nas quais os esforços na pesquisa social em geral e nos estudos sobre juventude em particular, centram-se no esforço de compreender a etapa intermediária entre a infância e a fase adulta, fase esta que por sua vez, tambiém se constitui em categrorias, fruto de construções e significaçõess sociais em contextos históricos e sociedades determinadas, em um processo de permanente mudanças e resignificações.

São resgatados os avaços no campo da pesquisa em temáticas de adolescência e juventude para os tempos atuais e são propostas algumas questões sobre a passagem da fase da adolescência/juventude para a fase (idade) adulta, que ajudem a delimitar as dimensões e variáveis que podem dar mais clareza a análise e seus eventuais impactos no desenho e na definição de políticas direcionadas a estes sujeitos sociais.

PALAVRAS CHAVE: ADOLESCÊNCIA, JUVENTUDE, TRAJETÓRIAS JUVENIS

\section{ABSTRACT}

In this text we discuss about the notions of adolescence and youth, as well as the disciplinary approach to the aforementioned concepts at the present time, where it's no longer a newness - but a necessity - to pluralize: the need to talk and conceive different «adolescences» and «youths», in a wide range of heterogeneities that we can find and visualize among adolescents and young people. This takes validity and makes sense at the moment we conceive the categories of adolescence and youth as a socio-historic, cultural and relational construction in contemporary societies, where the efforts in social research in general, and the studies on youth in particular, have been centered in letting know the stage between the childhood and the adulthood, that - at their own time - are also categories originated by social significations and constructions in historic contexts and defined societies, within a process of constant changes and new significations.

We highlight the advances in the field of research in matters of adolescence and youth nowadays and set forth certain questions about the transition from adolescence/youth to the adult age, in order to help define the dimensions and variables that can provide more clarity to the analysis and their eventual impacts in the design and setting out of policies oriented to social individuals.

KEY WORDS: ADOLESCENCE, YOUTH, JUVENILE TRAJECTORIES 


\section{INTRODUCCIÓN}

EL CAMPO DE ESTUDIO y conceptualizaciones en torno a las nociones de adolescencia y juventud ha tenido un desarrollo notable, sobre todo en las últimas décadas, tanto desde un punto de vista analítico, como a su vez, desde la perspectiva de desplegar determinadas acciones consideradas como de política pública que vayan encaminadas al fomento, desarrollo, protección y promoción de las diversas condiciones sociales en las cuales se insertan los diferentes conjunto de adolescentes y jóvenes.

A partir de allí, ya no resulta una novedad, pero sí una necesidad, el pluralizar al momento de referirnos a estos colectivos sociales, es decir, la necesidad de hablar y concebir diferentes «adolescencias» y «juventudes», en un amplio sentido de las heterogeneidades que se pueden presentar y visualizar entre adolescentes y jóvenes. Aquello cobra vigencia y sentido, de momento que concebimos las categorías de adolescencia y juventud como una construcción sociohistórica, cultural y relacional en las sociedades contemporáneas, donde los intentos y esfuerzos en la investigación social en general, y en los estudios de juventud en particular, han estado centrado en dar cuenta de la etapa que media entre la infancia y la adultez, las que a su vez, también se constituyen en categorías fruto de construcciones y significaciones sociales en contextos históricos y sociedades determinadas, en un proceso de permanente cambio y resignificaciones.

Pero no todo este proceso de abordamiento de las nociones en juego podemos concebirlas bajo un manto de incertidumbres y ambigüedad, pues hay importantes avances en el campo de la investigación en temáticas de adolescencia y juventud a tiempos actuales, lo que no necesariamente se orienta a convenciones asumidas hegemónicamente en sus perspectivas analíticas y evidencias empíricas adquiridas, sino que más bien, se tiende a construir un campo de análisis en disputa, intentando delimitar las dimensiones y variables que pueden aportar mayores claridades al análisis y sus eventuales impactos en el diseño y definición de políticas hacia estos sujetos sociales.

Discusión y disputa que ha estado abriendo y avanzando en marcos conceptuales múltiples, heterogéneos y posibles de ser usados por la investigación social, los cuales se han desplegado desde los mismos conceptos de adolescencia y juventud, como desde los diferentes enfoques que intentan dar cuenta de estas condiciones sociales, como a su vez, la concurrencia de una multiplicidad de abordajes disciplina- 
rios en la comprensión de lo adolescente y lo juvenil. De igual modo, las estrategias y métodos de investigación social en materias de adolescencia y juventud también está siendo un campo de debate, donde el uso de estrategias de tipo cualitativas y centradas con mayor énfasis en las subjetividades de los sujetos ha cobrado marcada relevancia, sin desconocer la extendida utilización de estrategias de corte cuantitativa; pero dando a las primeras el crédito de haber ampliado el marco comprensivo desde el propio sujeto y sus entornos cercanos y lejanos, lo que ha llevado a una toma de ubicación diferente y que puede adentrarse con mayor profundidad analítica en las cotidianeidades adolescentes y juveniles, y desde allí interlocutar e interpelar a los contextos y estructuras sociales, como también a las instituciones sociales. Emparentado con lo anterior, también podemos visualizar una readecuación o giros en cuanto a los tipos de lecturas o ejes comprensivos de las cuestiones constitutivas de la condición adolescente y juvenil, donde ha cobrado una importante relevancia el abordamiento de estas condiciones desde una lectura sociocultural, con mayor desarrollo actualmente que las lecturas socioeconómicas y las sociopolíticas. Ejemplo de ello lo constituyen los estudios socioculturales y el ámbito de las culturas juveniles.

Con estas premisas iniciales, transitaremos por la discusión y problematización de las nociones de adolescencia y juventud, con la pretensión de avanzar en un marco analítico que aporte en la dirección de una mejor comprensión de los sujetos y sus condiciones, como a su vez, en el pensar acciones y planteamientos de política pública orientadas a los adolescentes y jóvenes.

\section{LA CONSTRUCCIÓN DE LAS NOCIONES}

Los conceptos de adolescencia y juventud corresponden a una construcción social, histórica, cultural y relacional, que a través de las diferentes épocas y procesos históricos y sociales han ido adquiriendo denotaciones y delimitaciones diferentes: «la juventud y la vejez no están dadas, sino que se construyen socialmente en la lucha entre jóvenes y viejos» (Bourdieu, 2000:164). A la base de esta evolución conceptual, la historiografía $-\mathrm{y}$ la filosofía - nos aportan los antecedentes más remotos, principalmente por el trabajo de fuentes documentales accesibles, donde a partir de la tensión siempre presente en el análisis social sobre la constitución de categorías sociales y nociones que den cuenta del proceso en que los sujetos atraviesan por un 
ciclo vital definido histórica y culturalmente (cf. Sandoval, 2002; Feixa, 1999; Levi y Schmitt, 1996a y b). La misma noción de infancia nos remite a este considerando, y sus dinámicas de paso desde la infancia a la denominada edad adulta o adultez. El intersticio entre ambos estadios es lo que se suele concebir como el campo de estudio y conceptualización de la adolescencia y juventud, con delimitaciones en ambas no del todo claras, que en muchos aspectos se superponen, y dependiendo de los enfoques utilizados para esos efectos.

Disciplinariamente se le ha atribuido y endosado la responsabilidad analítica de la adolescencia a la psicología, en la perspectiva de un análisis y delimitación partiendo por el sujeto particular y sus procesos y transformaciones como sujeto; dejando a otras disciplinas de las ciencias sociales - y también las humanidades - la categoría de juventud, en especial a la sociología, antropología cultural y social, historia, educación, estudios culturales, comunicación, entre otros; donde a partir de sujetos particulares, el interés se centra en las relaciones sociales posibles de establecerse en éstos y las formaciones sociales, en el trazar vínculos o rupturas entre ellos (Bajoit, 2003). Sin embargo, la misma utilización de los conceptos de adolescencia y juventud, en muchas ocasiones tienden a usarse de manera sinónima y homologadas entre sí, especialmente en el campo de análisis de la psicología general, y en sus ramas de psicología social, clínica y educacional; cuestión que no ocurre con mayor frecuencia en las ciencias sociales.

Conceptualmente la adolescencia se constituye como campo de estudio, dentro de la psicología evolutiva, de manera reciente, pudiendo asignarse incipientemente sólo a finales del siglo XIX y con mayor fuerza a principios del siglo XX, bajo la influencia del psicólogo norteamericano Stanley Hall, quien con la publicación (1904) de un tratado sobre la adolescencia, se constituyó como hito fundacional del estudio de la adolescencia y pasara a formar parte de un capítulo dentro de la psicología evolutiva. Para Hall, la adolescencia es,

Una edad especialmente dramática y tormentosa en la que se producen innumerables tensiones, con inestabilidad, entusiasmo y pasión, en la que el joven se encuentra dividido entre tendencias opuestas. Además, la adolescencia supone un corte profundo con la infancia, es como un nuevo nacimiento (tomando esta idea de Rousseau) en la que el joven adquiere los caracteres humanos más elevados (Delval, 1998:545).

Teniendo en consideración las diferentes concepciones que pueden relevarse en torno a la adolescencia — clásicas y contemporáneas-, 
podemos encontrar algunos rasgos más o menos comunes a ellas, sea desde el punto vista biológico y fisiológico, en cuanto a desarrollo físico, durante ella se alcanza la etapa final del crecimiento, con el comienzo de la capacidad de reproducción: pudiendo decirse que la adolescencia se extiende desde la pubertad hasta el desarrollo de la madurez reproductiva completa. No se completa la adolescencia hasta que todas las estructuras y procesos necesarios para la fertilización, concepción, gestación y lactancia no han terminado de madurar (Florenzano, 1997).

Desde el punto de vista del desarrollo cognitivo o intelectual en la adolescencia, se ha venido caracterizando por la aparición de profundos cambios cualitativos en la estructura del pensamiento. Piaget denomina a este proceso, periodo de la operaciones formales, donde la actuación intelectual del adolescente se acerca cada vez más al modelo del tipo científico y lógico. Junto al desarrollo cognitivo, comienza con la adolescencia la configuración de un razonamiento social, teniendo como relevancia los procesos identitarios individuales, colectivos y societales, los cuales aportan en la comprensión del nosotros mismos, las relaciones interpersonales, las instituciones y costumbres sociales; donde el razonamiento social del adolescente se vincula con el conocimiento del yo y los otros, la adquisición de las habilidades sociales, el conocimiento y aceptación/negación de los principios del orden social, y con la adquisición y el desarrollo moral y valórico de los adolescentes (Moreno y Del Barrio, 2000).

Como una concepción más compleja e integral, el concepto de adolescencia, en una perspectiva conceptual y aplicada, también incluye otras dimensiones de carácter cultural, posibles de evolucionar de acuerdo a los mismos cambios que experimentan las sociedades en cuanto a sus visiones sobre este conjunto social.

El concepto de adolescencia es una construcción social. A la par de las intensas
transformaciones biológicas que caracterizan esa fase de la vida, y que son uni-
versales, participan de ese concepto elementos culturales que varían a lo largo
del tiempo, de una sociedad a otra y, dentro de una misma sociedad, de un gru-
po a otro. Es a partir de las representaciones que cada sociedad construye al
respecto de la adolescencia, por tanto, que se definen las responsabilidades y los
derechos que deben ser atribuidos a las personas en esa franja etaria y el modo
como tales derechos deben ser protegidos (Ação Educativa et al., 2002:7).

Estas formas de conceptualizar, delimitar y las miradas comprensivas hacia la adolescencia, pueden ser concebidos como los enfoques con 
los cuales se ha operado, habiendo en ellos una multiplicidad de factores, características y elementos, unos más relevados que otros, pero que transitan por los énfasis en las transformaciones físicas y biológicas, intelectuales y cognitivas, de identidad y personalidad, sociales y culturales, morales y valóricas. Para Delval (1998), estas concepciones sobre la adolescencia pueden sintetizarse en tres teorías o posiciones teóricas sobre la adolescencia: la teoría psicoanalítica, la teoría sociológica y la teoría de Piaget.

La teoría psicoanalítica concibe la adolescencia como resultado del desarrollo que se produce en la pubertad y que llevan a una modificación del equilibrio psíquico, produciendo una vulnerabilidad de la personalidad. A su vez, ocurre un despertar de la sexualidad y una modificación en los lazos con la familia de origen, pudiendo presentarse una desvinculación con la familia y de oposición a las normas, gestándose nuevas relaciones sociales y cobrando importancia la construcción de una identidad y la crisis de identidad asociada con ella (cf. Erikson, 1971). Desde esta perspectiva, la adolescencia es atribuida principalmente a causas internas. Por su parte, desde la teoría sociológica, la adolescencia es el resultado de tensiones y presiones que vienen del contexto social, fundamentalmente en lo relacionado con el proceso de socialización que lleva a cabo el sujeto y la adquisición de roles sociales, donde la adolescencia puede comprenderse primordialmente a causas sociales externas al mismo sujeto. La teoría de Piaget, releva los cambios en el pensamiento durante la adolescencia, donde el sujeto tiende a la elaboración de planes de vida y las transformaciones afectivas y sociales van unidas a cambios en el pensamiento, donde la adolescencia es el resultado de la interacción entre factores sociales e individuales (Delval, 1998:550-552).

\section{APROXIMACIÓN CONCEPTUAL AL FENÓMENO JUVENIL}

Ya consignada la difusa diferenciación conceptual $-\mathrm{y}$ en ocasiones también empírica- de la construcción y utilización de los conceptos de adolescencia y juventud, con todo el andamiaje teórico, metodológico e instrumental desplegado por las diferentes corrientes de pensamiento, sea a través de la evolución histórica de los conceptos, como el desarrollo desde los abordamientos disciplinarios al respecto; no es extraño una superposición y traslado de características de una noción a la otra, y viceversa. Por ello es necesario este resguardo y precaución en su tratamiento, pero que por claridad de la presentación deci- 
dimos dedicar el acápite anterior fundamentalmente a la categoría de adolescencia, para dar paso a esa aproximación conceptual de lo juvenil, que en muchos aspectos también incluye a la de adolescencia.

La juventud como hoy la conocemos es propiamente una «invención» de la posguerra, en el sentido del surgimiento de un nuevo orden internacional que conformaba una geografía política en la que los vencedores accedían a inéditos estándares de vida e imponían sus estilos y valores. La sociedad reivindicó la existencia de los niños y los jóvenes, como sujetos de derecho y, especialmente, en el caso de los jóvenes, como sujetos de consumo (Reguillo, 2000:23).

En sus diferentes tratamientos, la categoría juventud ha sido concebida como una construcción social, histórica, cultural y relacional, para designar con aquello la dinamicidad y permanente evolución/involución del mismo concepto. De acuerdo con Mørch (1996), es preciso tener en consideración que la conceptualización de la juventud pasa necesariamente por su encuadramiento histórico, en la medida en que esta categoría es una construcción histórica, que responde a condiciones sociales específicas que se dieron con los cambios sociales que produjeron la emergencia del capitalismo, el cual otorgó el denominado espacio simbólico que hiciera posible el surgimiento de la juventud (Mørch, 1996). Conjuntamente a lo anterior - a lo menos - la juventud es concebida como una categoría etaria (categoría sociodemográfica), como etapa de maduración (áreas sexual, afectiva, social, intelectual y físico/motora) y como subcultura (Sandoval, 2002:159-164).

En cuanto categoría etaria, que también es válida primariamente para la adolescencia, pueden hacerse algunos distingos y precisiones de acuerdo a los contextos sociales y las finalidades con que se desea utilizar esta dimensión sociodemográfica. Convencionalmente se ha utilizado la franja etaria entre los 12 y 18 años para designar la adolescencia; y para la juventud, aproximadamente entre los 15 y 29 años de edad, dividiéndose a su vez en tres subtramos: de 15 a 19 años, de 20 a 24 años y de 25 a 29 años. Incluso para el caso de designar el período juvenil, en determinados contextos y por usos instrumentales asociados, éste se amplía hacia abajo y hacia arriba, pudiendo extenderse entre un rango máximo desde los 12 a los 35 años, como se aprecia en algunas formulaciones de políticas públicas dirigidos al sector juvenil. Inclusive y debido a una necesidad de contar con definiciones operacionales como referentes programáticos en el campo de las políticas de adolescencia y juventud, el los países iberoamericanos se presenta una gran diferencia en los rangos edad utilizados. Por 
ejemplo, entre los 7 y 18 años en El Salvador; entre los 12 y 26 en Colombia; entre los 12 y 35 en Costa Rica; entre los 12 y 29 en México; entre los 14 y 30 en Argentina; entre los 15 y 24 en Bolivia, Ecuador, Perú, República Dominicana; entre los 15 y 25 en Guatemala y Portugal; entre los 15 y 29 en Chile, Cuba, España, Panamá y Paraguay; entre los 18 y 30 en Nicaragua; y en Honduras la población joven corresponde a los menores de 25 años (CEPAL y OIJ, 2004:290291). En Brasil se utilizaría el tramo entre los 15 y 24 años de edad (Instituto Cidadania, 2004:8-9; Camarano et al., 2004:1).

Lógicamente que por sí sola la categoría etaria no es suficiente para el análisis de lo adolescente y juvenil, pero sí necesaria para marcar algunas delimitaciones iniciales y básicas, pero no orientadas éstas en la dirección de homogeneizar estas categorías etarias para el conjunto de los sujetos que tienen una edad en un determinado rango. Incluso, en ocasiones se han utilizado denominaciones diferentes para intentar romper con estas superposiciones entre adolescentes y jóvenes, por ejemplo con la definición como «la persona joven» (cf. CPJ, 2004); o con la construcción de modelos o «tipos ideales» de juventud a través de la historia, de acuerdo a los tipos de sociedad posibles de identificar, donde nos encontramos,

Desde el modelo de «los púberes» de las sociedades primitivas sin Estado, los «efebos» de los Estados antiguos, lo «mozos» de las sociedades campesinas preindustriales, los «muchachos» de la primera industrialización, y los «jóvenes» de las modernas sociedades postindustriales (Feixa, 1999:18).

Cuando nos enfrentamos al concepto de juventud, éste es abordado desde distintas perspectivas, sin embargo, no se visualiza claramente una construcción teórica que problematice la realidad de los jóvenes e integre con ello un marco de análisis para su comprensión, y que tenga una tendencia hacia una visión más general de la juventud. Esto significa que no se trata de negar la realidad que conforman a los jóvenes, ni tampoco definirlos como sujetos que constituyen una etapa del individuo humano, intermedia entre la niñez y la edad adulta, sino más bien, elaborar un cimiento teórico conceptual que posicione al concepto y que sirva para interpretar los fenómenos juveniles antes de trabajar con el objeto real que son los jóvenes (Brito, 1996).

El concepto de juventud ha adquirido innumerable significados: sirve tanto para designar un estado de ánimo, como para calificar lo novedoso y lo actual, incluso se le ha llegado a considerar como un valor en sí mismo. Este concepto debe ser tratado desde la diversidad 
de sus sectores, donde cabría preguntarse: ¿desde dónde empezamos a construir una definición de juventud, sin que las diferencias de clases sociales y los contextos socioculturales estén sobre las identidades de las categorías de juventud?

La noción más general y usual del término juventud, se refiere a una franja de edad, un período de vida, en que se completa el desarrollo físico del individuo y ocurren una serie de transformaciones psicológicas y sociales, cuando éste abandona la infancia para procesar su entrada en el mundo adulto. Sin embargo, la noción de juventud es socialmente variable. La definición del tiempo de duración, de los contenidos y significados sociales de esos procesos se modifican de sociedad en sociedad y, en la misma sociedad, a lo largo del tiempo y a través de sus divisiones internas. Además, es solamente en algunas formaciones sociales que la juventud se configura como un período destacado, o sea, aparece como una categoría con visibilidad social (Abramo, 1994:1).

La juventud no es un «don» que se pierde con el tiempo, sino una condición social con cualidades específicas que se manifiestan de diferentes maneras según las característica históricas sociales de cada individuo (Brito, 1996). Un joven de una zona rural no tienen la misma significación etaria que un joven de la ciudad, como tampoco los de sectores marginados y las clases de altos ingresos económicos. Por esta razón, no se puede establecer un criterio de edad universal que sea válido para todos los sectores y todas las épocas: la edad se transforma sólo en un referente demográfico.

La juventud se encuentra delimitada por dos procesos: uno biológico y otro social. El biológico sirve para establecer su diferenciación con el niño, y el social, su diferenciación con el adulto (Allerbeck y Rosenmayr, 1979:21).

La definición de la categoría juventud se puede articular en función de dos conceptos: lo juvenil y lo cotidiano. Lo juvenil nos remite al proceso psicosocial de construcción de la identidad y lo cotidiano al contexto de relaciones y prácticas sociales en las cuales dicho proceso se realiza, con anclaje en factores ecológicos, culturales y socioeconómicos. La potencia de esta óptica radica sustancialmente en ampliar la visión sobre el actor, incorporando la variable sociocultural a la demográfica, psicológica o a categorizaciones estructurales que corresponden a las que tradicionalmente se han utilizado para su definición. Entonces lo que incluye es la variable vida cotidiana que define la vivencia y experiencia del período juvenil. Al decir de Reguillo, para no quedar atrapados en los análisis en juventud, que nos dejan de un lado, con sujetos sin estructura; y del otro, de estructuras sin sujeto (Reguillo, 2000:45). 
Para situar al sujeto juvenil en un contexto histórico y sociopolítico, resultan insuficientes las concreciones empíricas, si éstas se piensan con independencia de los criterios de clasificación y principios de diferenciación social que las distintas sociedades establecen para sus distintos miembros y clases de edad (Reguillo, 2000:49).

Esta mirada permite reconocer la heterogeneidad de lo juvenil desde las diversas realidades cotidianas en las que se desenvuelven las distintas juventudes. De esta manera posibilita a su vez asumir que en el período juvenil tienen plena vigencia todas las necesidades humanas básicas y otras específicas, por lo que resulta perentorio reconocer tanto la realidad presente de los jóvenes como su condición de sujetos en preparación para el futuro. Esto supone la posibilidad de observar a la juventud como una etapa de la vida que tiene sus propias oportunidades y limitaciones, entendiéndola no sólo como un período de moratoria y preparación para la vida adulta y el desempeño de roles predeterminados, tal como define la perspectiva clásica o eriksoniana.

Hechas estas precisiones, podemos señalar que el proceso de construcción de identidad se configura como uno de los elementos característicos y nucleares del período juvenil. Dicho proceso se asocia a condicionantes individuales, familiares, sociales, culturales e históricas determinadas. Por otro lado, es un proceso complejo que se constata en diversos niveles simultáneamente. Se ha distinguido la preocupación por identificarse a un nivel personal, generacional y social. Tiene lugar un reconocimiento de sí mismo, observándose e identificando características propias (identidad individual); este proceso trae consigo las identificaciones de género y roles sexuales asociados. Además se busca el reconocimiento de un sí mismo en los otros que resultan significativos o que se perciben con características que se desearía poseer y que se ubican en la misma etapa vital. Ello constituye la identidad generacional.

También existe un reconocimiento de sí mismo en un colectivo mayor, en un grupo social que define y que determina a su vez en el compartir una situación común de vida y convivencia. La identidad refiere obligatoriamente al entorno, el ambiente. Los contenidos que originan la identidad generacional implican modos de vida, particularmente prácticas sociales juveniles y comportamientos colectivos. También involucran valores y visiones de mundo que guían esos comportamientos.

En este contexto, las tareas de desarrollo y específicamente el proceso de construcción de identidad juvenil, se entiende como un 
desafío que si bien es común a los adolescentes y jóvenes (o a la mayoría) en cuanto a la emergencia de la necesidad de diferenciarse de los demás, y por supuesto de sentirse único, no se manifiesta de la misma manera o de forma homogénea, al contrario, la diversidad es su principal característica. Hoy está asumiendo esta redefinición de las tareas de desarrollo como insumo esencial de las tareas formativas que se plantea alcanzar.

\section{LOS ENFOQUES DISCIPLINARIOS Y CLASIFICATORIOS}

Cerca de tres décadas atrás (1971), el Instituto Latinoamericano de Planificación Económica y Social (ILPES), resaltaba la necesidad de recurrir a los conocimientos generados torno al fenómeno juvenil por parte de las distintas disciplinas involucradas en su estudio, como una forma de ayudar en la clarificación del mismo y que resultaran más apropiados para orientar acciones dirigidas a las juventud latinoamericana. Para tal efecto, presentaba una síntesis de seis enfoques disciplinarios - de mayor usos sociales, por entonces - encaminados a deducir las perspectivas más adecuadas en sus usos analíticos y con orientaciones de planificación social programática.

Consideraban en su síntesis de enfoques y perspectivas, el enfoque psicobiológico, caracterizando a la juventud como un período vital, centrado en los cambios psicológicos y maduración biológica del individuo. La perspectiva antropológica-cultural relevaba la influencia sobre los jóvenes del contexto sociocultural donde se socializan. El enfoque psicosocial o de la personalidad ocupado de la personalidad juvenil, en cuanto sus motivaciones y actitudes. El enfoque demográfico consideraba a la juventud como una franja etaria o un segmento de la población total, teniendo como estudio la estructura y la dinámica de las tasas vitales. El enfoque sociológico otorgaba especial significado al proceso de incorporación del joven a la vida adulta. $Y$ finalmente, la perspectiva politíco-social prestaba atención a las formas de organización y acción de los movimientos juveniles y su influencia en la dinámica social (Gurrieri y Torres-Rivas, 1971:30-31).

Otra posible clasificación, sobre las principales aproximaciones teóricas y disciplinarias del estudio de la juventud, es la que nos entregan las investigadoras Alpízar y Bernal (2003), quienes explicitan este recorrido como el esfuerzo de la construcción de la juventud desde la academia, graficada en siete aproximaciones teóricas, las que en orden de presentación corresponden a una cierta secuencialidad evo- 
lutiva del concepto. Valga sólo su enunciación: la juventud entendida como etapa del desarrollo psicobiológico humano, la juventud como momento clave para la integración social, la juventud como dato sociodemográfico, la juventud como agente de cambio, la juventud como problema de desarrollo, juventud y generaciones (no las generaciones de Mannheim y Ortega y Gasset de principios del siglo pasado, sino las llamadas generaciones contemporáneas: generación X, escéptica, red, entre otras), y juventud como construcción sociocultural (Alpízar y Bernal, 2003:106-118).

Desde el punto de vista de la antropología contemporánea, Feixa (1999), avanza en la definición de una antropología de la juventud, presentado para tal efecto su objeto y cuáles debieran ser sus orientaciones principales.

Desde mi punto de vista, el objeto de una antropología de la juventud apunta a una doble dirección: en primer lugar al estudio de la construcción cultural de la juventud (es decir, de las formas mediante las cuales cada sociedad modela las maneras de ser joven); en segundo lugar, al estudio de la construcción juvenil de la cultura (es decir, de las formas mediante las cuales los jóvenes participan en los procesos de creación y circulación culturales). El primer camino, mucho más trillado, se centra en el impacto de las instituciones adultas sobre el mundo juvenil, y puede conducir al estudio transcultural de la juventud y a la crítica de las visiones etnocéntricas y ahistóricas que predominan en buena parte de la literatura académica sobre la misma. El segundo camino, mucho menos explorado, se centra en la influencia del mundo juvenil sobre la sociedad en su conjunto, y conduce al estudio de las microculturas juveniles, entendidas como manifestación de la capacidad creativa y no solamente imitativa de los jóvenes (Feixa, 1999:11).

Tomando la perspectiva sociológica, Enrique Martín Criado (1998), en su texto Producir la juventud, crítica de la sociología de la juventud, propone una revisión de la sociología de la juventud en Occidente, bajo la modalidad de contar una historia de la sociología de la juventud, haciendo para ello los recortes analíticos en una suerte de cronología histórica, donde los protagonistas son las escuelas y corrientes de pensamiento, como sus máximos exponentes, que principalmente durante el siglo XX, se han ocupado del estudio de la juventud. Sólo a modo de enunciación, el recorrido lo inicia con los llamados «generacionalistas», representados por las elaboraciones de Mannheim y Ortega y Gasset en la década del veinte del siglo pasado, donde teorizan la sociedad en términos de generaciones, teniendo la juventud (cierto tipo de juventud) un rol preponderante en la construc- 
ción de una nueva sociedad (cf. Ghiardo, 2004). Por aquellos mismos años, aparece en escena la «Escuela de Chicago» - con Thrasher como máximo exponente - y su elaboración sobre las bandas y las subculturas específicas: la subcultura delincuente y la subcultura juvenil, la primera ocupada del estudio de los jóvenes de clases populares y la segunda, de los jóvenes estudiantes clasemedieros. Un tercer momento lo constituye la denominación de «la construcción psicológica de la adolescencia», consignando a Stanley Hall como el autor más célebre sobre el tema de la época, donde la lucha entre la naturaleza del instinto y la cultura de la civilización es lo que caracteriza la turbulencia del adolescente. Por su parte, en un cuarto momento, la cultura juvenil, según Parsons, se caracterizaría por su hedonismo e irresponsabilidad, en un análisis funcionalista que tiende a concebir a la juventud como grupo unificado, negando con ello la importancia de las diferenciaciones de clases sociales. Desde una perspectiva completamente diferente y en confrontación directa con el estructuralfuncionalismo, surge la «nueva sociología de la juventud británica», conocida como la «Escuela de Birmingham» y denominada como corriente teórica de «nueva teoría subcultural», situando la clase social en el centro de su análisis, y a la juventud y las subculturas juveniles son principalmente subculturas de clases: las subculturas son campos de batalla políticos entre clases. Cierra Martín Criado esta revisión con las aportaciones del «Centro de Sociología de la Educación y la Cultura» (CSEC), — teniendo como figura más relevante a Bourdieu-, para el cual el problema de la juventud debe inscribirse en el contexto de las luchas sociales por la reproducción, luchas entre grupos sociales por el control del acceso a las distintas posiciones en la sociedad (Martín Criado, 1998:21-39).

Desde los estudios socioculturales en juventud, y específicamente en relación a las prácticas de los jóvenes, Reguillo (2000), nos señala que «analizar, desde una perspectiva sociocultural, el ámbito de las prácticas juveniles, hace visibles las relaciones entre estructuras y sujetos, entre control y formas de participación, entre el momento objetivo de la cultura y el momento subjetivo» (Reguillo, 2000:16).

\section{TRAYECTORIAS DE VIDA Y CONDICIONES JUVENILES}

La perspectiva analítica de las trayectorias de vida y nuevas condiciones juveniles, se configura como un intento de avanzar en la comprensión del fenómeno adolescente y juvenil, la que se constituye en una 
nueva o recreada miradas al conjunto de situaciones por las que atraviesan estos segmentos sociales, con énfasis distintos y posibles implicancias en el plano de impacto en las políticas orientadas a los adolescentes y jóvenes. Como comprensión analítica, puede insumar elementos de concepción y definición, tanto del sujeto en cuestión, como del contexto en el cual deben vivir sus condiciones juveniles.

Los procesos de transición desde la etapa adolescente/juvenil a la vida adulta, está siendo un ámbito de debate y discusión entre los investigadores en temáticas de juventud, siendo relevante en aquellas discusiones dos nociones conceptuales y sus implicancias que ellas traen aparejadas.

La primera («nuevas condiciones juveniles»), el posicionar la atención en los cambios y transformaciones societales experimentadas a nivel global en las últimas décadas, representadas en la lógica del paso de la sociedad industrial hacia la sociedad informacional o del conocimiento (Castells, 2001a), los cuales están influenciando con mayor fuerza en los modos de vida de las personas y estructurando cambios acelerados en el funcionamiento de las sociedad. Transformaciones y cambios socioeconómicos y culturales que afectan a toda la estructura social y que adquiere características específicas en el modo de entender y comprender la etapa juvenil y la categoría juventud, como tradicionalmente se le comprendió en cuanto construcción sociohistórica. Sumado a ello, se pone en cuestión la organización de la vida en tres momentos vitales: formación, actividad y jubilación, modelo que ha perdido vigencia fruto de la transformación de las estructuras sociales y del conjunto del ciclo de la vida (Casanovas et al., 2002); lo que ha llevado a replantearse la condición juvenil en este nuevo contexto y adentrarse en el concebir a ésta como un conjunto de cambios a nivel de las vivencias y relacionamientos de los jóvenes en un nuevo escenario social, que trae consigo ciertos elementos de «nuevas condiciones juveniles», diferenciándolas de la «situación social de los jóvenes».

Intervienen en estas diferenciaciones, una conceptualización sobre la noción de «juventud», que como construcción social y categoría histórica, se desarrolla a lo largo de los procesos de modernización, principalmente a mediados del siglo XX, en el mundo occidental. La «condición juvenil», como categoría sociológica y antropológica, referida a la estructura social como a los valores y a la cultura particular de los sujetos jóvenes en los procesos de transformaciones sociales contemporáneas (formativas, laborales, económicas, culturales). 
Y la «situación social de los jóvenes», nos remite al análisis territorial y temporal concreto, siendo el cómo los diversos jóvenes viven y experimentan su condición de jóvenes, en un espacio y un tiempo determinado. De allí se conjugan procesos que vinculan a la noción de juventud bajo ciertos elementos que se visualizan con cierta estabilidad: alargamiento o prolongación de la juventud, como una fase de la vida producto de una mayor permanencia en el sistema educativo, el retraso en su inserción sociolaboral y de conformación de familia propia, mayor dependencia respecto a sus hogares de orígenes y menor autonomía o emancipación residencial.

Y la segunda («trayectorias de vida»), nos remite a los cambios experimentados en los modelos y procesos de entrada a la vida adulta por parte de estos sujetos jóvenes, lo que nos lleva a entender la etapa de vida designada como juventud, a una etapa de transición (Pais, 2002a, 1998; Casal, 2002, 1999). Transición en el paso de la infancia a la vida adulta, donde se combinan enfoques teóricos que conciben este paso como tiempo de espera antes de asumir roles y responsabilidades adultas, proceso en el cual se hace uso de una moratoria social aceptada social y culturalmente (Erikson, 1971, 1993); como a su vez, enfoques en desarrollo que nos remiten a transiciones juveniles de nuevo tipo, donde se conjuga este proceso en un contexto diferente a nivel de los sujetos y las estructuras sociales en las cuales se despliegan estas transiciones, cobrando mayor relevancia el paso desde el mundo de la formación al mundo del trabajo, entendido como la plena inserción sociolaboral y sus variables anexas a ello.

La noción de trayectorias nos remite al tránsito desde una situación de dependencia (infancia) a una situación de emancipación o autonomía social (Redondo, 2000); tránsito que se ha modificado, principalmente, por el alargamiento de la condición de estudiante en el tiempo y el retraso en la inserción laboral y de autonomías de emancipación social de los jóvenes.

Podemos distinguir entre la transición, considerada como movimiento (la trayectoria biográfica que va de la infancia a la edad adulta) y la transición considerada como proceso (de reproducción social); donde las trayectorias de los jóvenes son algo más que historias vitales personales: son un reflejo de las estructuras y los procesos sociales; procesos que se dan de manera conjunta, es decir, consideran procesos a nivel de la configuración y percepciones desde la propia individualidad y subjetividad del sujeto, y las relaciones que se establecen entre aquéllas y los contextos a nivel de las estructuras sociales en las cuales 
se desarrollan aquellas subjetividades (Redondo, 2000; Martín Criado, 1998). De ese modo, en la transición a la vida adulta por parte de los jóvenes, el tiempo presente no está determinado solamente por las experiencias acumuladas del pasado del sujeto, sino que también forman parte de él las aspiraciones y los planes para el futuro: el presente aparece condicionado por los proyectos o la anticipación del futuro (Pais, 2000; Casal, 2002).

Desde esta perspectiva, la transición desde la etapa juvenil a la vida adulta, ha dejado de ser un tipo de «trayectoria lineal», o concebida como una trayectoria de final conocido y de manera tradicional, donde el eje de la transición fue el paso de la educación al trabajo; donde actualmente, con mayor propiedad, este tránsito está más vinculado a una fase imprevisible, vulnerable, de incertidumbre mayor que en las trayectorias tradicionales o lineales, donde pueden denominarse tipos de «trayectorias reversibles, laberínticas o yo-yo» (López, 2002; Pais, 2002a). A su vez, estos posibles itinerarios de vida o de tránsito a la vida adulta desde la etapa juvenil, también pueden tener finales diversos debido a la pluralidad de juventudes y condiciones juveniles posibles de identificarse, donde hallamos, según sus resultados, «trayectorias exitosas» o «trayectorias fallidas», dependiendo de las situaciones biográficas de los jóvenes, donde la variable que más discriminará y será factor de predictividad, los desempeños y credenciales educativas obtenidas por los sujetos en este tránsito hacia la vida adulta; además de la acumulación, apropiación y transferencia diferenciada de los capitales cultural, económico, social y simbólico (Bourdieu, 2000, 1998; Martín Criado, 1998).

La «no linealidad» de las transiciones a la vida adulta pone de manifiesto que ya no se da una relación causa/efecto, de un antes y un después, y los modelos estandarizadores de las transiciones se han convertido en trayectorias desestandarizadas; que van configurando proyectos de vida diferenciados entre los jóvenes y su paso a la vida adulta (Pais, 2002a). De tal modo que el concepto de transición enfatiza la adquisición de capacidades y derechos asociados a la edad adulta. El desarrollo personal y la individualización se ven como procesos que se apoyan en el aprendizaje y la interiorización de unas determinadas normas culturales (socialización) como requisitos previos a convertirse y de ser considerado como un miembro de la sociedad con todas sus consecuencias.

Los procesos de diversificación y la individualización de la vida social se encuentran a la base de la diversificación de itinerarios hacia 
la madurez, rompiendo con ello con la linealidad de la transición para la mayoría y aparecen itinerarios diversos y diversificados (López, 2002). El concepto individualización acentúa que es el sujeto joven el que tiene que construir su propia biografía, sin tener que poder apoyarse en contextos estables. Esto no significa, sin embargo, que ya no importen los condicionamientos y el origen social (Du Bois-Reymond et al., 2002).

De allí la relevancia de incorporar en el análisis la noción de capital y las especies de capitales, entendido aquél como una relación social que define la apropiación diferencial y diferenciada por los sujetos del producto socialmente producido. Bourdieu distingue otras especies de capital, además del capital económico, que como éste, suponen apropiación diferencial: «un capital cultural (con subespecies, como el capital lingüístico), un capital escolar (capital cultural objetivado en forma de títulos escolares), un capital social (relaciones sociales movilizables para la obtención de recursos), un capital simbólico (prestigio)» (Martín Criado, 1998:73).

Es así que podemos dejar planteadas algunas interrogantes sobre el paso de la adolescencia/juventud a la edad adulta: ¿en qué posibles campos tiene lugar esa transición?, como a su vez, ¿qué influye más en la transición de la educación al trabajo: la cualificación o los orígenes sociales?, ¿los proyectos de los jóvenes o sus trayectorias pasadas?, ¿de qué manera e intensidad influyen los activos o capitales social, cultural, económico y simbólico presentes en la configuración de diferentes tipos de trayectorias juveniles a la vida adulta?

VALPARAíso (CHILE), OCTUBRE 2004

RECIBIDO: OCTUBRE 2004

ACEPTADO: DICIEMBRE 2004

\section{REFERENCIAS BIBLIOGRÁFICAS}

ABramo, Helena W. (1994): Cenas juvenis. São Paulo: Scritta.

AÇão EduCATIVA et al. (2002): "Adolescência. Escolaridade, profissionalização e renda. Propostas de políticas públicas para adolescentes de baixa escolaridades e baixa renda». São Paulo: Ação Educativa.

Allerbeck, KlaUS y LeOPOLD RosenMAYR (1979): Introducción a la sociología de la juventud. Buenos Aires: Editorial Kapelusz.

AlPÍZAR, LydiA y MARINA BERNAL (2003): «La construcción social de las juventudes». Última Década No19. Viña del Mar: Ediciones CIDPA. 
Bajoit, Guy (2003): Todo cambia. Análisis sociológico del cambio social y cultural en las sociedades contemporáneas. Santiago: LoM Ediciones.

BENDIT, RENÉ (2000): «Adolescencia y participación: una visión panorámica en los países de la Unión Europea». Anuario de Psicología, Vol. 31, N². Barcelona: Universitat de Barcelona.

— y DERMOT StOKES (2004): «Jóvenes en situación de desventaja social: políticas de transición entre la construcción social y las necesidades de una juventud vulnerable». Revista de Estudios de Juventud $\mathrm{N}^{\circ} 65$. Madrid: INJUVE.

BERNALES, JOSEP (2002): «Políticas de juventud y nueva condición juvenil». Revista de Estudios de Juventud $\mathrm{N}^{\circ} 59$. Madrid: INJUVE.

BigGART, ANDY et al. (2002): "'Trayectorias fallidas', entre estandarización y flexibilidad en Gran Bretaña, Italia y Alemania Occidental». Revista de Estudios de Juventud $\mathrm{N}^{\mathrm{o}} 56$. Madrid: INJUVE.

Bourdieu, Pierre (2000): Cuestiones de sociología. Madrid: Istmo.

- (1998): Capital cultural, escuela y espacio social. México: Siglo XXI. (1988): La distinción. Madrid: Taurus.

- y JeAn-Claude PASSERon (2003): Los herederos. Los estudiantes y la cultura. Buenos Aires: Siglo XXI.

BRITO LEMUS, ROBERTO (2002): «Identidades juveniles y praxis divergentes: acerca de la conceptualización de juventud». En ALFREDO NATERAS (coordinador): Jóvenes, culturas e identidades urbanas. México: UAM.

_ (1996): «Hacia una sociología de la juventud». JOVENES, Revista de Estudios Sobre Juventud $\mathrm{N}^{\mathrm{o}} 1$. México: IMJ.

CACHÓN, LORENZO (2004): «Las políticas de transición: estrategia de actores y políticas de empleo juvenil en Europa». Revista de Estudios de Juventud No65. Madrid: INJUVE.

- (2002): «Las políticas de transición, entre las biografías individuales y los mercados de trabajo. Estrategia de los actores, lógicas y políticas de empleo juvenil en Europa». Ponencia presentada en la Conferencia Europea para Investigadores y Técnicos «Jóvenes y políticas de transición en Europa». INJUVE, Madrid, 6 al 8 de junio.

CAMARANO, ANA AmÉlia et al. (2004): «Caminhos para a vida adulta: as múltiplas trajetórias dos jovens brasileiros». Texto para Discussão №1038. Rio de Janeiro: IPEA (incluido en este mismo volumen).

CASAl, JoAQUim (2002): «TVA y políticas públicas sobre juventud». Revista de Estudios de Juventud $\mathrm{N}^{\circ} 59$. Madrid: INJUVE.

— (1999): «Juventud, transición y políticas sociales». En: La nueva condición juvenil y las políticas de juventud. Barcelona: Diputación de Barcelona.

_ co de la transición a la vida adulta». Politica y Sociedad $\mathrm{N}^{\circ} 1$. Madrid: UCM.

CASANOVAS, JoRDI et al. (2002): «Razones y tópicos de las políticas de juventud». Revista de Estudios de Juventud No59. Madrid: INJUVE.

CASTELlS, MANUEL (2001a): La era de la información. Economía, sociedad y cultura. Volumen I: La sociedad red. México: Siglo XXI.

CEPAL (2000a): «Adolescencia y juventud en América Latina y el Caribe: problemas, oportunidades y desafíos en el comienzo de un nuevo siglo». Serie Población y Desarrollo $\mathrm{N}^{\circ}$ 9. Santiago: CEPAL. 
— (2000b): Juventud, población y desarrollo en América Latina y el Caribe: problemas, oportunidades y desafios. Santiago: CEPAL.

— y OIJ (2004): La juventud en iberoamérica. Tendencias y urgencias. Santiago: CEPAL Y OIJ.

—- UNICEF y SECIB (2001): Construir equidad desde la infancia y la adolescencia en Iberoamérica. Santiago: CEPAL, UNICEF, SECIB.

Consejo Nacional de la Política Pública de la Persona Joven (CPJ) (2004): Política pública de la persona joven. San José de Costa Rica: CPJ.

DÁviLA LEÓN, OSCAR (2002): «Biografías y trayectorias juveniles». Última Década $\mathrm{N}^{\circ} 17$. Viña del Mar: Ediciones CIDPA.

Delval, JuAn (1998): El desarrollo humano. Madrid: Siglo XXI.

Du BoIs-REYMOND, MANUEla et al. (2002): «Transiciones modernizadas y políticas de desventaja: Países Bajos, Portugal, Irlanda y jóvenes inmigrantes en Alemania». Revista de Estudios de Juventud N56. Madrid: INJUVE.

— y ANDREU LÓPEZ BLASCO (2004): «Transiciones tipo yo-yo y trayectorias fallidas: hacia las políticas integradas de transición para los jóvenes europeos». Revista de Estudios de Juventud $\mathrm{N}^{\mathrm{o}} 65$. Madrid: INJUVE.

ERIKSON, ERIK H. (1993): Sociedad y adolescencia. México: Siglo XXI (14ª edición). (1971): Identidad, juventud y crisis. Buenos Aires: Paidós.

FeIXA, CARLes (1999): De jóvenes, bandas y tribus. Barcelona: Ariel.

FLORENZANO, RAMÓN (1997): El adolescente y sus conductas de riesgo. Santiago: PUC.

GHIARDO, FELIPE (2004): «Generaciones y juventud: una relectura desde Mannheim y Ortega y Gasset». Última Década N²0. Viña del Mar: Ediciones CIDPA.

GURRIERI, AdOLFO y EDELBERTO TORRES-Rivas (1971): «Situación de la juventud dentro del complejo económico-social de América Latina». En ADOLFO GURRIERI et al.: Estudios sobre la juventud marginal latinoamericana. Santiago: Siglo XXI.

HERNÁNDEZ ARISTU, Jesús (2002): «Entre la familia, la formación y el empleo estructuras de apoyo a las transiciones-》. Revista de Estudios de Juventud No56. Madrid: INJUVE.

INJUV (2004): Cuarta encuesta nacional de juventud 2003. Santiago: INJUV.

Instituto Cidadania (2004): Projeto Juventude. Documento de conclusão. Versão inicial para discussão, complementação e ajustes. São Paulo: Instituto Cidadania.

LeVi, Giovanni y JeAn-Claude Schmitt (editores) (1996a): Historia de los jóvenes I. De la antigüedad a la edad moderna. Madrid: Taurus.

— - - (editores) (1996b): Historia de los jóvenes II. La edad contemporánea. Madrid: Taurus.

LÓPEZ BlASCO, ANDREU (2002): «De los itinerarios lineales a las trayectorias yo-yo». Ponencia presentada en la Conferencia Europea para Investigadores y Técnicos «Jóvenes y políticas de transición en Europa». INJUVE, Madrid, 6 al 8 de junio.

LuTTE, G. (1991): Liberar la adolescencia. La psicología de los jóvenes de hoy. Barcelona: Herder.

MANNHEIM, KARL (1982): «O problema sociológico das gerações». En M. ForACHI: Mannheim. São Paulo: Ática.

- (1944): Diagnóstico de nuestro tiempo. México: FCE.

MARTín CRIADO, ENRIQUe (1998): Producir la juventud. Crítica de la sociología de la juventud. Madrid: Istmo. 
Martín SerRano, MAnuel (2002): «La prolongación de la etapa juvenil de la vida y sus efectos en la socialización». Revista de Estudios de Juventud №56. Madrid: INJUVE.

Matterlart, ARMAnd y Michele MATterlart (1970): Juventud chilena: rebeldía y conformismo. Santiago: Editorial Universitaria.

Mead, Margaret (1995): Adolescencia y cultura en Samoa. Barcelona: Paidós.

Mørch, MATILDE et al. (2002): "Sistemas educativos en sociedades segmentadas: 'trayectorias fallidas' en Dinamarca, Alemania Oriental y España». Revista de Estudios de Juventud $\mathrm{N}^{\circ} 56$. Madrid: INJUVE.

Mørch, Sven (1996): «Sobre el desarrollo y los problemas de la juventud, el surgimiento de la juventud como concepción sociohistórica». JOVENES, Revista de Estudios Sobre Juventud No1. México: IMJ.

Moreno, Amparo y Cristina Del Barrio (2000): La experiencia adolescente. A la búsqueda de un lugar en el mundo. Buenos Aires: Editorial Aique.

ORTEGA Y GASSET, JosÉ (1955): El tema de nuestro tiempo. Madrid: Espasa Calpe.

PAIS, JosÉ MACHADO (2002a): «Laberintos de vida: paro juvenil y rutas de salida (jóvenes portugueses)». Revista de Estudios de Juventud N56. Madrid: INJUVE.

- (2002b): «Praxes, graffitis, hip-hop. Movimientos y estilos juveniles en Portugal». En CARLES FeIXA et al. (editores): Movimientos juveniles en la Península Ibérica: graffitis, grifotas, okupas. Barcelona: Ariel.

- (2000): «Las transiciones y culturas de la juventud: formas y escenificaciones». Revista Internacional de Ciencias Sociales Nº164. París: UNESCO.

— y AXEL POHL (2004): «Los dilemas del aprendizaje informal». Revista de Estudios de Juventud No65. Madrid: INJUVE.

PNUD (2004): Informe nacional de desarrollo humano Panamá 2004. De la invisibilidad al protagonismo: la voz de la juventud. Panamá: PNUD.

Programa Presidencia Colombia Joven (2004): Política nacional de juventud. Bases para el plan decenal de juventud, 2005-2015. Bogotá: PPCJ.

REDONDO, JESÚs (2000): «La condición juvenil: entre la educación y el empleo». Última Década N¹2. Viña del Mar: Ediciones CIDPA.

Reguillo Cruz, Rossana (2002): «Cuerpos juveniles, políticas de identidad». En Carles Feixa, Fidel Molina y Carles Alsinet (editores): Movimientos juveniles en América Latina: pachucos, malandros, punketas. Barcelona: Ariel.

- (2000): Emergencia de culturas juveniles. Estrategias del desencanto. Buenos Aires: Grupo Editorial Norma.

RUA, MARIA DAS GRAÇAS (1998): «As políticas públicas e a juventude dos anos 90». En CNPD: Jovens acontecendo na trilha das políticas públicas, Vol. 2. Brasilia: Comissão Nacional de População e Desenvolvimento.

SANDOVAL, MARIO (2002): Jóvenes del siglo XXI. Sujetos y actores en una sociedad en cambio. Santiago: UCSH.

Stauber, Barbara; Siyka Kovacheva y Harm VAn Lieshout (2004): «Flexibilidad y seguridad: el supuesto dilema de las políticas de transición». Revista de Estudios de Juventud $\mathrm{N}^{\circ} 65$. Madrid: INJUVE.

TOURAINE, AlAIN (1996): «Juventud y democracia en Chile». Revista Iberoamericana de Juventud $\mathrm{N}^{\circ} 1$. Madrid: OIJ.

Unicef (2000): Adolescencia en América Latina y El Caribe: orientaciones para la formulación de políticas. Panamá: UNICEF. 
VARGAS, CARMEM ZELI (2004): «Juventude e contemporaneidade: possibilidades e limites». Última Década №20. Viña del Mar: Ediciones CIDPA.

WALTHER, ANDREAS (2004): «Dilemas de las políticas de transición: discrepancias entre las perspectivas de los jóvenes y de las instituciones». Revista de Estudios de Juventud $\mathrm{N}^{\mathrm{o}} 65$. Madrid: INJUVE. 